\title{
Confirming tracheal intubation - a simple manoeuvre
}

A simple technique is described for confirming oral tracheal intubation carried out under direct laryngoscopy. With the laryngoscope blade still in the mouth following intubation, posterior displacement of the tracheal tube towards the palate will usually bring the tube and vocal cords into direct view, providing confirmation of correct tube placement. In 50 consecutive oral trach ... intubations, the tube was seen to pass between the vocal cords in 29 cases, confirming correct tube placement. In the remaining 21 cases, the larynx was obscured during intubation. Posterior displacement of the tube confirmed correct placement in all 21 cases.

\section{Key words}

ANAESTHETIC TECHNIQUES: intubation; COMPLICATIONS: oesophageal intubation.
Unrecognized oesophageal intubation continues to be a significant cause of anaesthetic death and cerebral injury. ${ }^{1,2}$ Identification of the correct placement of a tracheal tube has been described by Pollard and Junius, ${ }^{3}$ Howells and Rietchmuller ${ }^{4}$ and more recently by Catton and Dunn. ${ }^{1}$ Methods which depend on the auscultation of breath sounds, or on the observation of chest wall movements or patient colour are not entirely reliable as air can enter the trachea from a tube placed in the oesophagus. Auscultation over the epigastrium is very helpful in detecting oesophageal intubation but is not routinely performed. Monitoring the end-tidal $\mathrm{CO}_{2}$ or passing a fiberoptic scope to see tracheal rings or the carina are reliable methods but are not always available or convenient.

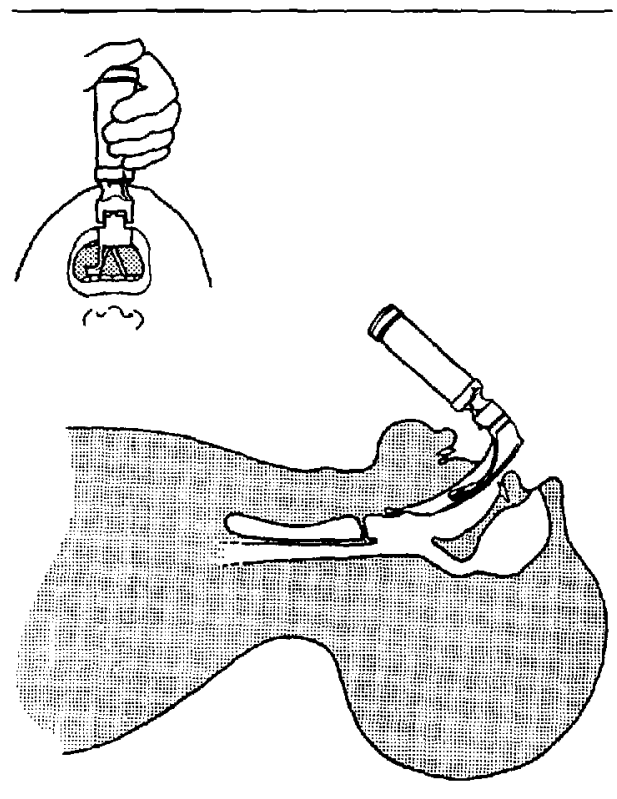

FIGURE 1 View of exposed larynx during laryngoscopy. 


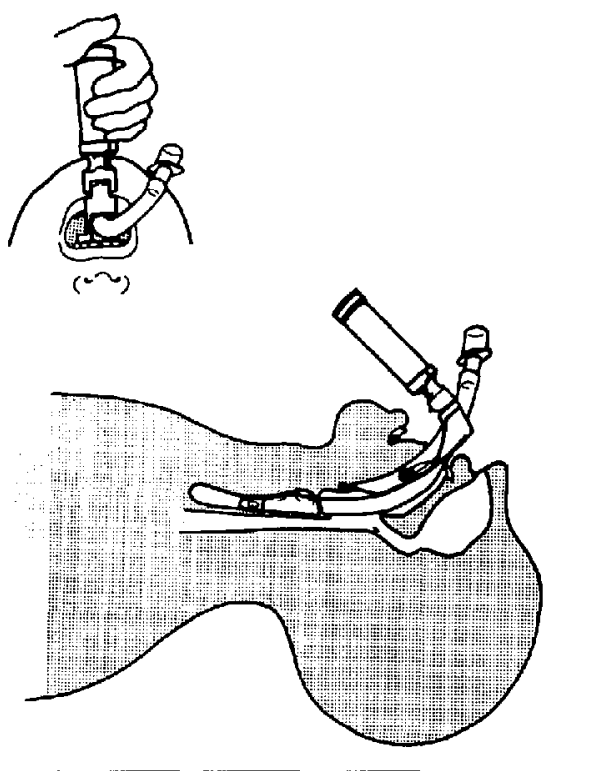

FIGURE 2 Tracheal tube blocks view of tarynx.

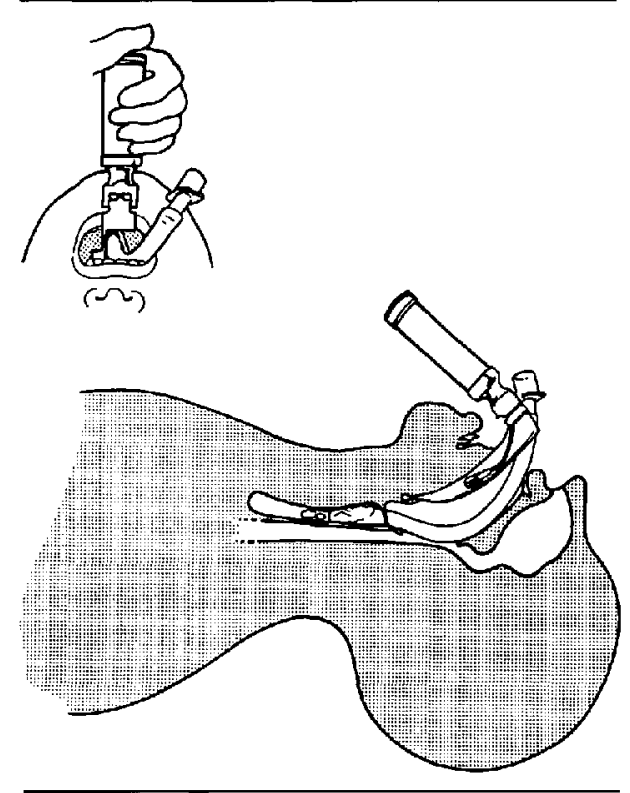

FIGURE 3 Posterior displacement of tracheal tube restores view of larynx
One certain method of confirming tracheal intubation is to see the tube pass between the vocal cords. Unfortunately, the vocal cords are often obscured by the tube as it enters the larynx and direct visual confirmation of tracheal intubation may not be realized. Such confirmation can usually be obtained, however, if prior to removing the laryngoscope from the mouth, the tube is displaced posteriorly towards the palate. This manoeuvre frequently brings the tube and cords into view. A gentle backward push on the tube against the forward traction of the laryngoscope blade exposes the vocal cords by altering the direction of the tube as it enters the larynx. The view afforded by this technique is depicted in Figures 1 to 3. The larynx, as seen just prior to intubation, is shown in Figure 1. It is hidden by the tube during intubation as shown in Figure 2. Restoration of the larynx to view by posterior displacement of the tube is shown in Figure 3.

In 50 consecutive oral intubations under direct laryngoscopy, the tube was seen to pass between the vocal cords in 29 , confirming correct tube placement. In 20 cases, the larynx was sufficiently obscured during intubation that correct placement could not be guaranteed. In these cases posterior displacement of the tube confirmed its position within the larynx. In one case, neither the vocal cords nor the arytenoid cartileges could be seen by direct laryngoscopy prior to intubation. However, following intubation, the tube and adjacent right vocal cord were brought into view by displacing the tube posteriorly as demonstrated in Figure 3 . I have found that it is often possible to see the larynx by this method even though it could not be seen prior to intubation.

It is probable that many anaesthetists already use this method to ensure correct tracheal tube placement but its use is far from universal. Routine application of this simple technique could eliminate avoidable oesophageal intubation as a cause of anaesthetic morbidity and mortality.

\section{Acknowledgement}

I wish to thank Miss Lori Johnson for her expert assistance in preparing the illustrations. 


\section{Reiferences}

1 Catton DV, Dunn AJ. Esophageal intubation. Can Anaesth Soc Newsletter 1982; 8: No. 1.

2 Utting JE, Gray TC, Shelley FC. Human misadventure in anacsthesia. Can Anaesth Soc J 1979; 26: 472-8

3 Pollard BJ, Junius $F$. Accidental intubation of the oesophagus. Anaesth Intens Care 1980; 8: 183-6.

4 Howells $T H$, Rietchmuiler RJ. Signs of endotracheal intubation. Anaesth 1980; 35: 984-6.

\section{Résumé}

Nous décrivons ici une technique simple afin de confirmer l'intubation intra-trachéale au moyen de la laryngoscopie directe. Avec la lame du laryngoscope dans la bouche, après l'intubation. le déplacement postérieur du tube trachéal vers le palais montre normalement une vue directe du tube et des cordes vocales, ce qui confirme que le tube est correctement placé. En faisant cinquante intubations trachéales, on a observé dans vingt-neuf cas que le tube passait entre les cordes vocales, confirmant le placement correct du tube. Chez les vingt-et-un autres cas, la vue du larynx erait dissimulée pendant l'intubation. Le déplacement postérieur du sube confirme le placement correct obsené dans chacun des vingt-et-un cas. 